\title{
Numerical Simulation of Turbulent Isothermal Flow in Mechanically Ventilated Room
}

\author{
Khudheyer S. Mushatet \\ College of Engineering, Thiqar University \\ Nassiriya, Iraq \\ khudheyer2004@yahoo.com
}

\begin{abstract}
A two-dimensional turbulence $\mathrm{k}-\varepsilon$ model is used to predict the distribution of air velocity, temperature and turbulence kinetic energy in a ventilated room using different positions of inlet and outlet apertures. The Navier Stockes, energy and turbulence equations are solved using finite volume techniques with staggered grid. The characteristics of air flow are analyzed under different parameters such as inlet and outlet positions, aspect ratio and air supply velocities. This study is focused on the prediction of turbulent recirculating flows in large indoor spaces. The results show that the wall jet region and recirculation regions are affected by the position of inlet and outlet apertures. Also the results indicate that recirculation regions are increased with increasing Reynolds number and decrease with decreasing aspect ratio.
\end{abstract}

\section{Nomenclature:}

$\mathrm{A}_{\mathrm{r}}$

$\mathrm{c}_{\mu}, \mathrm{c}_{1 \varepsilon}, \mathrm{c}_{2 \varepsilon}$

G

$\mathrm{h}$

$\mathrm{H}$

$\mathrm{k}$

$\mathrm{L}$

$P$

$\operatorname{Pr}$

$\operatorname{Re}$

$\mathrm{T}$

$\mathrm{u}, \mathrm{v}$

$\mathrm{x}, \mathrm{y}$

$\mathrm{y}^{+}$

$\mathrm{y}_{\mathrm{p}}$ aspect ratio

turbulence constants

generation term

width of aperture

height of the room

turbulence kinetic energy

length of the room

pressure

Prandtl number

Reynolds number

temperature

mean velocity components

Cartesian coordinates

dimensionless distance from the wall

distance from position $\mathrm{p}$ to the wall 


$\begin{array}{ll}\text { Greek symbols } & \\ \varepsilon & \text { turbulence dissipation rate } \\ \Gamma & \text { exchange coefficient } \\ \mu & \text { molecular viscosity } \\ \mu_{\mathrm{t}} & \text { eddy viscosity } \\ \sigma_{\mathrm{T}} & \text { turbulent Prandtl number } \\ \sigma_{\mathrm{k}}, \sigma_{\mathrm{t}} & \text { turbulent Schmidt number } \\ \kappa & \text { Von karman constant } \\ \Phi & \text { dependent variable } \\ \mathrm{E} & \text { empirical constant } \\ \mathrm{S}_{\phi} & \text { source term }\end{array}$

\section{Introduction}

Understanding of indoor air distribution characteristics is essential to the design of ventilation systems and to the control of room thermal and air quality conditions. The indoor environment design requires detailed information about air distribution such as air flow, velocity, temperature and pollutant concentration. The literature includes many investigations related to the topic of ventilation inside an enclosure. One of the earliest attempts to numerically simulate air flow in rooms was conducted by Nielsen ${ }^{[1]}$ using stream function vorticity approach for the dependent variables, along with a two equation (k- $\varepsilon$ ) model for turbulence based on the numerical procedure developed by Gosman et al. ${ }^{[2]}$. Hjertager and Magnussen ${ }^{[3]}$ solved the transport equations for momentum and the turbulence parameters $(\mathrm{k}-\varepsilon)$ using an upwind difference scheme and a simple algorithm to calculate the three-dimensional isothermal flows of a turbulent free jet and turbulent wall jet in an enclosure. They predicted the jet separation from the ceiling. Gosman et al. ${ }^{[4]}$ extended their twodimensional finite volume model to solve the isothermal flows within a 3D enclosure with small ventilation openings. They achieved good correlations, velocity profiles and jet velocity decay with experiments. Holmborg and Einborge ${ }^{[5]}$ studied the flow behavior in a conference room by both measurements and numerical methods. Their study indicated that the measurements and numerical simulations of indoor air quality need to be carefully planned and evaluated before they can be used in the development of a new system. Zhang et al. ${ }^{[6]}$ developed an experimental facility to provide measurements of the mean and turbulence behavior of room ventilation flows. They found that the flow inside the room was two-dimensional except very close to the end walls. 
Mora et al. ${ }^{[7]}$ checked the effectiveness of both zonal and coarse grid k- $\varepsilon$ to predict air flow and temperature profiles in a two-dimensional building zone. They concluded that zonal models are suitable tools to assess thermal efforts in rooms, and the coarse grids $k-\varepsilon$ is an appropriate method to quickly estimate details of air flow in rooms. A two equation $(\mathrm{k}-\varepsilon)$ turbulence model with large eddy simulation model were used by Sakamato ${ }^{[8]}$ to predict the unsteady recirculation isothermal turbulent flow inside a cubic room ventilated from a square supply opening in the center of the ceiling and identical floor level side wall extracts. The results showed that the $(\mathrm{k}-\varepsilon)$ model is better for predicting the room air flows than the large eddy simulation model. Chen ${ }^{[9]}$ used the average Navier-Stokes equations with a two equation turbulence model to predict the air flow in single rooms. The used method has proven its ability to estimate the indoor air characteristics in single rooms. Chen and $\mathrm{Xu}{ }^{[10]}$ reduced the size of simulation domains using Prandtl zero-equation turbulence model to predict the air flow characteristics inside rooms.

The aim of the current study is to get an insight into turbulent recirculating air flows inside an enclosure with different inlet and outlet positions of air openings. Solving of the governing equations is done numerically using a staggered grid method with finite volumes techniques. This method supplies us with a set of discretisation equations which means that the system of partial differential equations is transformed to a system of algebraic equations. The problem to be considered is shown in Fig. 1 \& 2. The geometry is specified by the height $\mathrm{H}$ and length $\mathrm{L}$. Different locations of aperture at inlet and outlet are used $(\mathrm{h}=0.75 \mathrm{H}, \mathrm{h}=0.5 \mathrm{H}, \mathrm{h}=0.25 \mathrm{H})$. The width of the aperture is $(\mathrm{h}=0.1 \mathrm{H})$.

\section{Mathematical Model}

To simplify the numerical simulation by using a two dimensional mathematical model, the flow is assumed to be incompressible, steady and Boussine approximation is valid. Employing the eddy viscosity concept (which means that the turbulent stresses are proportional to the mean velocity gradients), the time averaged continuity, momentum and energy equations are written as:

$$
\frac{\partial u}{\partial x}+\frac{\partial v}{\partial x}=0
$$




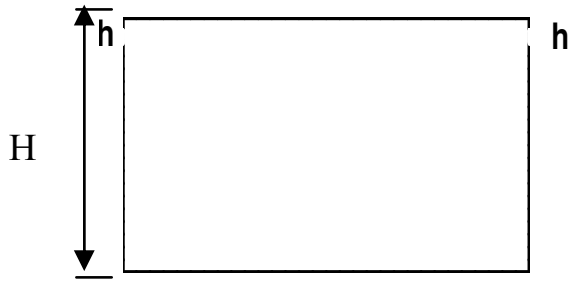

(a)

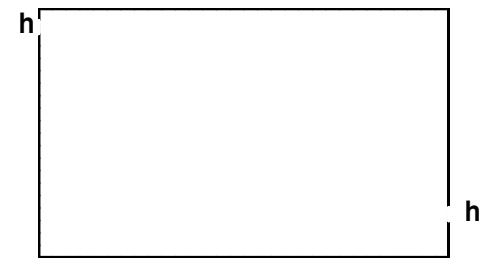

(b)

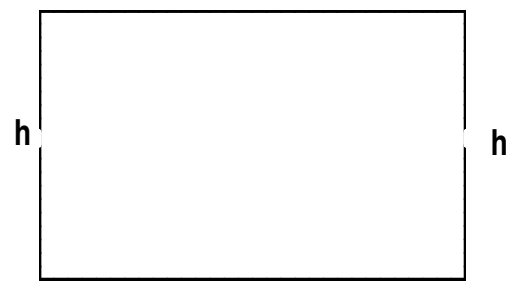

(c)

Fig. 1. Physical problem.

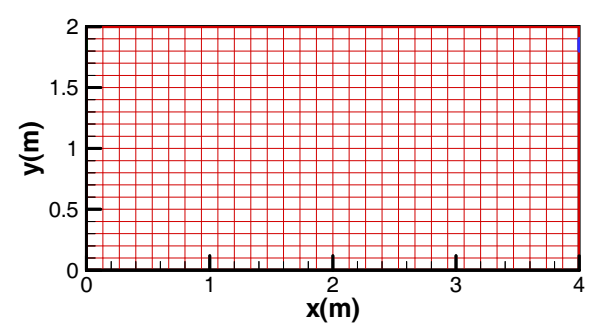

Fig. 2. Considered mesh $(31 \times 21)$.

$$
\begin{aligned}
& \rho u \frac{\partial u}{\partial x}+\rho v \frac{\partial u}{\partial y}=-\frac{\partial p}{\partial x}+2 \frac{\partial}{\partial x}\left(\mu_{\text {eff }} \frac{\partial u}{\partial x}\right)+\frac{\partial}{\partial y}\left(\mu_{\text {eff }} \frac{\partial u}{\partial y}\right)+\frac{\partial}{\partial y}\left(\mu_{\text {eff }} \frac{\partial v}{\partial x}\right) \\
& \rho u \frac{\partial v}{\partial x}+\rho v \frac{\partial v}{\partial y}=-\frac{\partial p}{\partial y}+\frac{\partial}{\partial x}\left(\mu_{\text {eff }} \frac{\partial v}{\partial x}\right)+2 \frac{\partial}{\partial y}\left(\mu_{\text {eff }} \frac{\partial v}{\partial y}\right)+\frac{\partial}{\partial x}\left(\mu_{\text {eff }} \frac{\partial u}{\partial y}\right) \\
& \rho u \frac{\partial T}{\partial x}+\rho v \frac{\partial T}{\partial y}=\frac{\partial}{\partial x}\left(\Gamma_{\text {eff }} \frac{\partial T}{\partial x}\right)+\frac{\partial}{\partial y}\left(\Gamma_{\text {eff }} \frac{\partial T}{\partial y}\right) \\
& \mu_{\text {eff }}=\mu+\mu_{t}
\end{aligned}
$$


$\Gamma_{e f f, T}=\frac{\mu}{\operatorname{Pr}}+\frac{\mu_{t}}{\operatorname{Pr}}$

Where: $\mu_{\text {eff }}$ is combined laminar and turbulent stresses and $\Gamma_{\text {eff }}$ is effective exchange coefficient. The turbulent kinetic energy and the rate of its dissipation for two dimensional isothermal turbulent flow can be written as follows ${ }^{[11]}$ :

$\rho u \frac{\partial k}{\partial x}+\rho v \frac{\partial k}{\partial y}=\frac{\partial}{\partial x}\left(\Gamma_{e f f, k} \frac{\partial k}{\partial x}\right)+\frac{\partial}{\partial y}\left(\Gamma_{e f f, k} \frac{\partial k}{\partial y}\right)+G-\rho \varepsilon$

$\rho u \frac{\partial \varepsilon}{\partial x}+\rho v \frac{\partial \varepsilon}{\partial y}=\frac{\partial}{\partial x}\left(\Gamma_{e f f, \varepsilon} \frac{\partial \varepsilon}{\partial x}\right)+\frac{\partial}{\partial y}\left(\Gamma_{e f f, \varepsilon} \frac{\partial \varepsilon}{\partial y}\right)+c_{1 \varepsilon} \frac{\varepsilon}{k} G+c_{2 \varepsilon} \frac{\varepsilon^{2}}{k}$

where: $G=v_{t}\left[2\left(\frac{\partial u}{\partial x}\right)+2\left(\frac{\partial v}{\partial y}\right)+\left(\frac{\partial u}{\partial y}+\frac{\partial v}{\partial x}\right)\right]$

$\Gamma_{e f f, k}=\mu+\frac{\mu_{t}}{\sigma_{k}}, \Gamma_{e f f, s}=\mu+\frac{\mu_{t}}{\sigma_{\varepsilon}}$

The eddy viscosity is obtained by the Prandtl-Kolmogorov hypothesis:

$$
\mu_{t}=\rho_{\mathcal{C}_{\mu}} \frac{k^{2}}{\varepsilon}
$$

\subsection{Boundary Conditions}

In order to complete the mathematical model, the following boundary conditions are defined as follows:

$$
\begin{aligned}
& \text { At inlet }{ }^{[12]}: \\
& \mathrm{u}=\mathrm{u}_{\text {in }} \\
& \mathrm{k}=0.05 \mathrm{u}^{2}{ }_{\text {in }} \\
& \varepsilon=\mathrm{k} .5 / \lambda \mathrm{H} \\
& \text { where } \lambda=0.05
\end{aligned}
$$

At the walls:

no slip boundary conditions are imposed.

$$
\frac{\partial k}{\partial n}=0
$$


$\varepsilon_{p}=\frac{c_{\mu}{ }^{3 / 4} k_{p}^{3 / 2}}{\kappa y_{p}} ; \mathrm{n}$ is coordinate normal to the wall and $\mathrm{p}$ is a point adjacent to the wall.

\section{Numerical Procedure}

Differential equations were integrated through the finite volume method (FVM). This gives a system of discretisation equations which means that the system of elliptic partial differential equations is transformed into a system of algebraic equations. The common GaussSiedl method helps in solving the algebraic equations system. The essence of the discretisation is to select an appropriate discretisation scheme (appropriate option of balance between connective and diffusion terms through the boundary of each control volume.) The general governing differential equations takes the form ${ }^{[13]}$ :

$\operatorname{div}(\rho U \Phi)=\operatorname{div}(\Gamma \operatorname{grad} \Phi)+S_{\Phi}$

In this paper an orthogonal grid with hybrid scheme is used. The one dimensional connective and diffusive fluxes can be expressed as follows:

$J_{x}=\rho U \Phi-\Gamma \frac{\partial \Phi}{\partial x}$

by using finite volume method the discretisation of east side flux by hybrid scheme gives the form:

$\left(\rho U \Phi-\Gamma \frac{\partial \Phi}{\partial x}\right)_{e}=(\rho U)_{e} \frac{\Phi_{p}+\Phi_{e}}{2}-\Gamma_{e} \frac{\Phi_{p}+\Phi_{e}}{\Delta X_{e}}$

A computer program is built to obtain the results of numerical procedure using SIMPLE algorithm. The first calculation is started from zero field and the every one takes the previous as initial condition. To prevent the instability and divergence due to non linearity in NavierStokes equations, relaxation factors were used on the components of velocity, pressure and turbulence quantities. The values of these factors are $0.5,0.8,0.7$, respectively. A typical run of 3500 takes about $180 \mathrm{CPU}$ seconds on PENTIUM 4 computer. To ensure that the turbulent fluid flow solutions are not significantly affected by the mesh, the numerical 
simulations were performed with different number of grid sizes ranging from $21 \times 31$ until $81 \times 61$ control volumes and the results were compared with published results ${ }^{[6,14-15]}$. The difference in the calculated parameters due to change was less than $2 \%$. Therefore we used the grid size with $21 \times 31$ control volumes and this step is done by Mora et al. ${ }^{[7]}$.

\section{Results and Discussion}

The results obtained from this study including velocity vectors, stream lines, pressure, kinetic energy and thermal field are discussed as follows:

Figure 3 exhibits the computed velocity vectors for different inlet and outlet openings. It is clear that the position of aperture affects the flow behavior in all the studied cases. In case (a) when the air is detached from the wall the inertia force is decreased and the flow begins to form a semi stagnant core region. However the stagnant core region is not uniform.

(a)

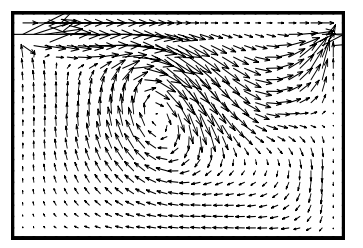

(b)

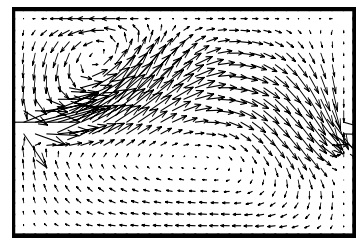

(c)

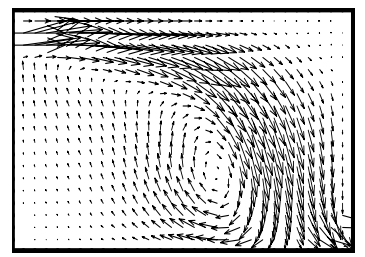

Fig. 3. Velocity vectors for different inlet and outlet apertures. 
In case (b) two recirculating regions are found and the size of the core region is larger. The core region is also not uniform. The flow from opening supply may be divided into three regions; the reverse flow in the corner, the central core region and the wall jet region. In the case of (c), a noticeable decrease in the axial velocity occurs in the reattachment zone followed by a significant increase in the wall jet region.

The streamlines for the studied cases are depicted in Fig. 4. As the figure displays, the streamlines show the tracing of the flow including a clear description or recirculating regions. The recirculation region is larger in case (b) because of the location of aperture under the same conditions. It is evident that when the streamlines are closer to each other, the flow is faster and vise versa.

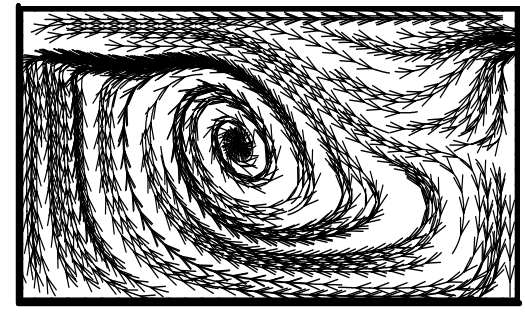

(a)

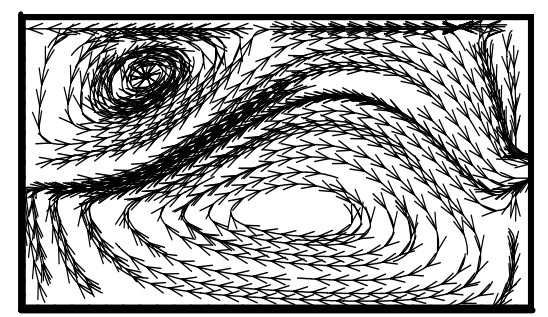

(b)

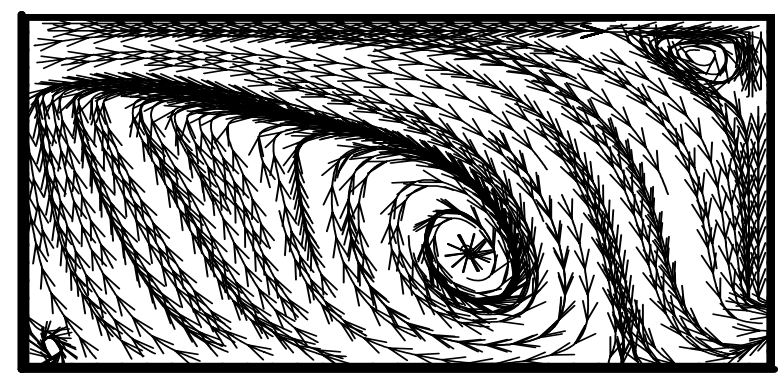

(c)

Fig. 4. Stream lines patterns $(a, b$, c) for different inlet and outlet positions. 


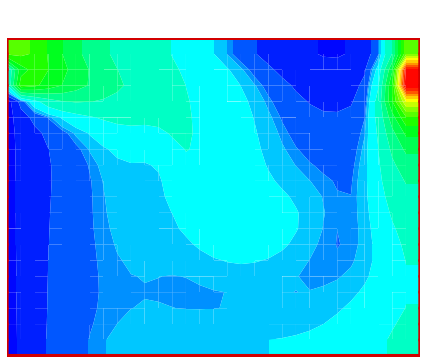

a (a)
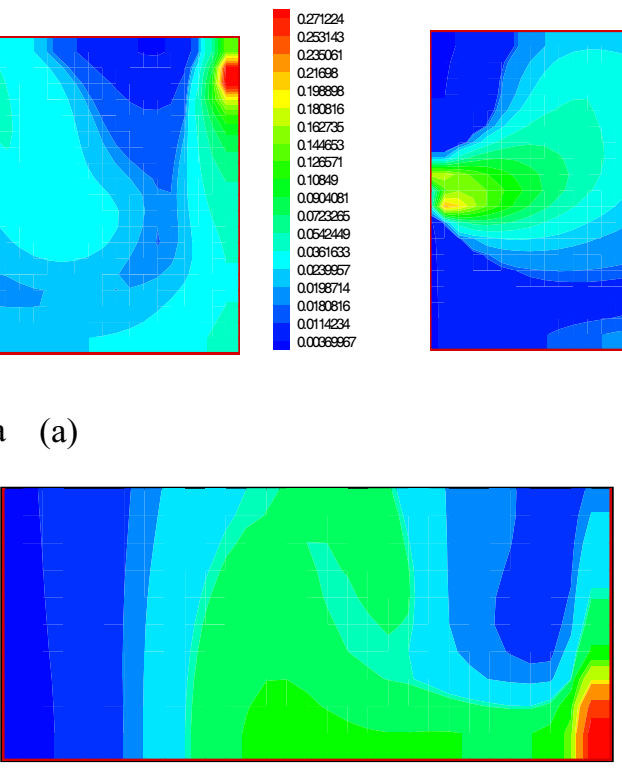

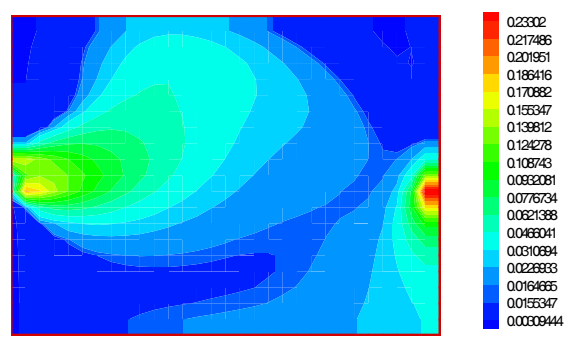

b. (b)

Fig. 5:a, b, c. Contours of turbulent kinetic energy .

Figure 5 shows the distribution of turbulent kinetic energy under the studied cases. It can be seen that location of apertures affects the distribution and values of turbulence kinetic energy. The height values of turbulent kinetic energy is to be found in case (c).

Figure 6 demonstrates the distribution of thermal flow field for different positions of inlet and outlet apertures. Nearly at all the studied cases the central core region is not stratified with uniform temperatures. There is no significant change in temperature values because the isothermal state is considered.

The pressure distribution for the studied cases is seen in Fig. 7. The isobars of the studied cases indicate the pressure drop and the values of these isobars are different according to the position of aperture.

The effect of Reynolds number on the flow field is seen in Fig. 8. As the figure shows the re-circulation regions are increased with the increase of Reynolds number for all studied cases. The structure of wall jet is nearly the same but the central core region is changed. 


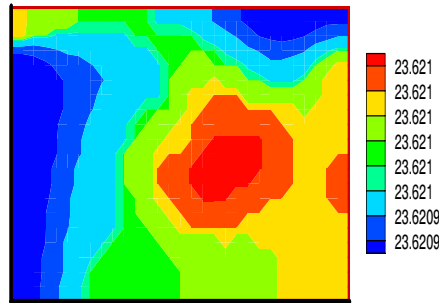

a

(a)

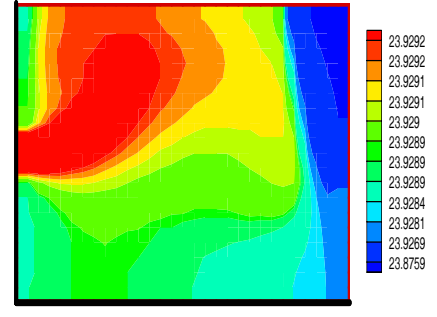

b

(b)

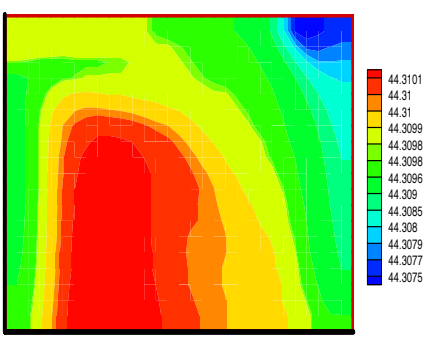

(c)

Fig. 6. Temperature field with different inlet and outlet positions.

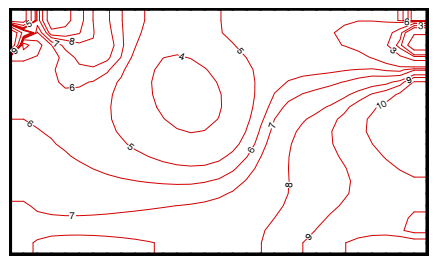

(a)

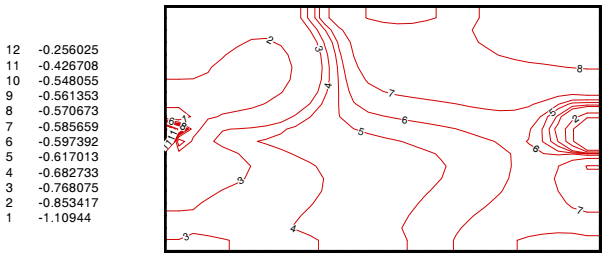

(b)

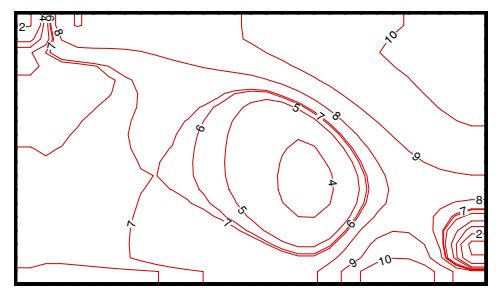

$\begin{array}{ll}12 & -0.0651561 \\ 11 & -0.260624 \\ 10 & -0.273681 \\ 9 & -0.32587 \\ 8 & -0.458402 \\ 7 & -0.4898489 \\ 6 & -0.502823 \\ 5 & -0.509971 \\ 4 & -0.521249 \\ 3 & -0.531878 \\ 2 & -0.581046 \\ 1 & -0.651561\end{array}$

(c)

Fig. 7. Isolines of static pressure in the considered domain. 
The aspect ratio of the room affects the flow field as shown in Fig. 9. As the figure shows the recirculating region is decreased and the detached flow in case (a) is stronger than that of $A_{p}=2$.

a. $\mathrm{U}=1 \mathrm{~m} / \mathrm{s}$

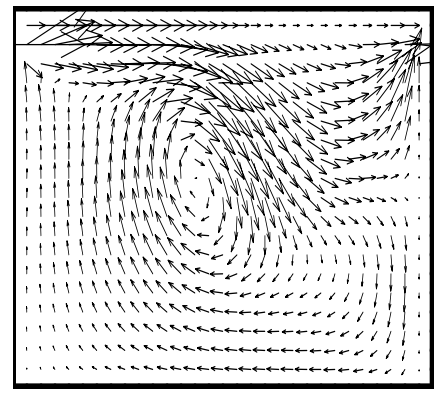

b. $\mathrm{U}=2 \mathrm{~m} / \mathrm{s}$

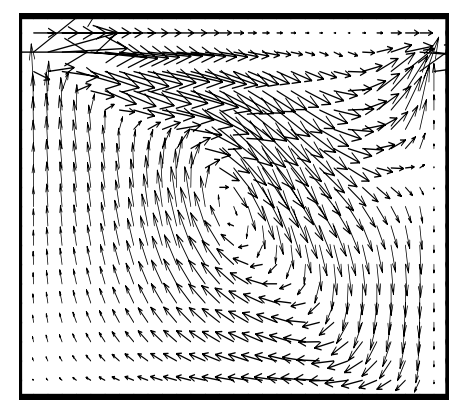

Fig .8. Effect of Reynolds number on the flow behavior (a. $R e=24400, b . \operatorname{Re}=48800$ )

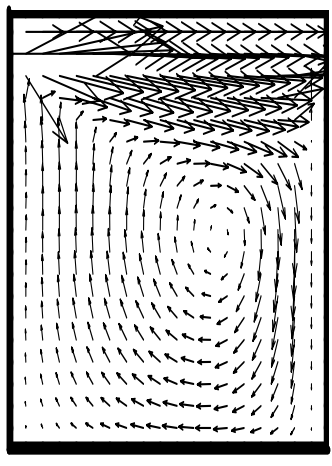

a. $A_{r}=1$.

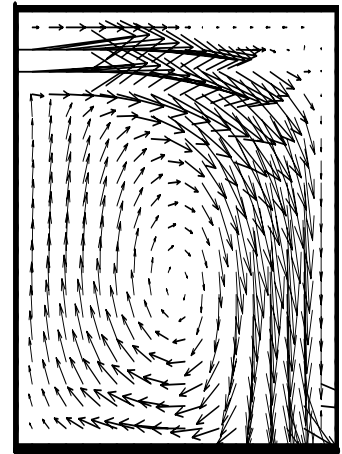

c. $\mathrm{A}_{\mathrm{r}}=1$

Fig. 9. Effect of aspect ratio on the flow field.

In Fig. 10, the computed results are compared with experimental published data ${ }^{[6]}$. As the figure shows, the comparison indicates four types of flow regions as follows:

- The reverse flow region in the upper corner where this flow behavior may be due to the reduction of static pressure in the region bounded by the flow curve and ceiling ${ }^{[6]}$.

- The re-circulation region, which is effected strongly by the position of the aperture.

- The outlet region, which is effected with smooth exit boundary conditions and the static pressure. 
- The wall jet region, where the axial velocity decreases after the reattachment zone.

The discrepancy between the predicted and experimental results is observed to be within $12 \%$.

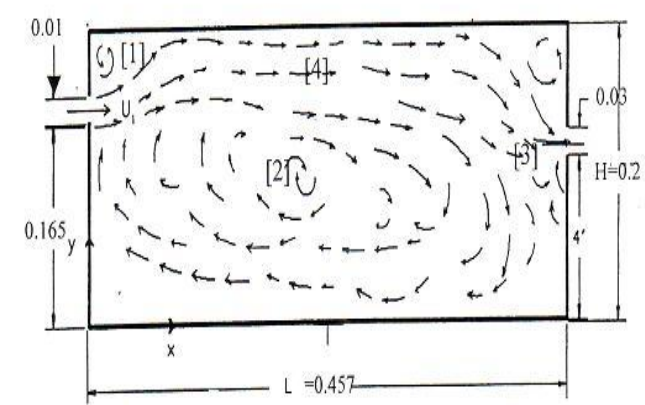

a) Experimental Ref. [6]

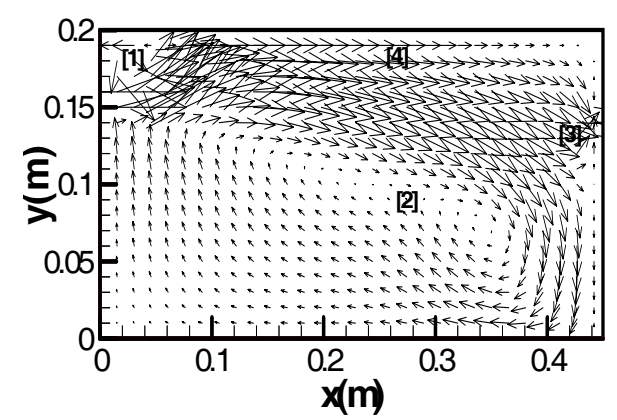

b ) Predicted

Fig. 10. Comparison of the results predicted by the present study with published experimental results.

Also the new code was validated against the published predicted results of Mohammed ${ }^{[15]}$ and Choi ${ }^{[14]}$. The comparisons indicated satisfactory agreement as shown in Fig. $11 \& 12$.

\section{Concluding Remarks}

In this paper, the $\mathrm{k}-\varepsilon$ model is used with finite volume technique to predict the two - dimensional turbulent flow inside a room with different 


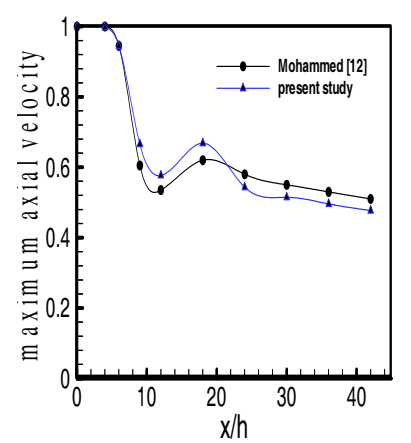

Fig. 11. Comparison of the present results with published predicted results for two-dimensional offset jet for $\mathrm{h} / \mathrm{H}=\mathbf{0 . 1 7 5}$.

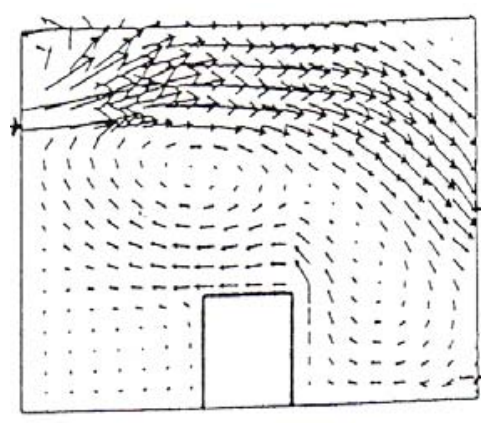

a) Published results.

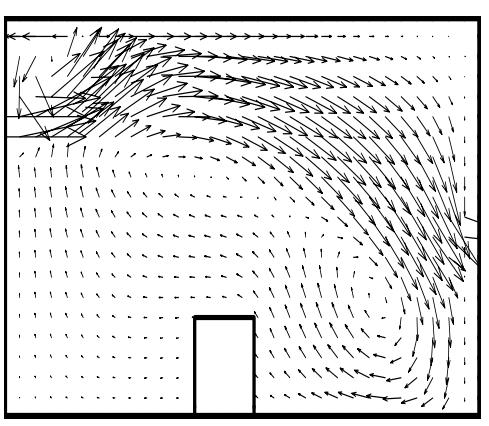

b) Present results, Ref. [14]

Fig. 12 (a, b). Comparison of the present and predicted published results.

positions of inlet and outlet apertures. The k- $\varepsilon$ model gives acceptable results to estimate the structure of turbulent re-circulating flow inside a ventilated room with different Reynolds number and aspect ratios. The obtained results indicate that the room recirculation regions increase with increase of Reynolds number and decrease with the decrease of aspect ratio. Also the results indicate that the axial velocity in the ventilated zone is decreased in case (b) more than in other cases while the axial velocity in the wall jet region is larger in case (c). 


\section{References}

[1] Nielsen, P.V., Flow in Air Conditioned Rooms, Ph.D. Thesis, Tech. Univ. of Denmark (1974).

[2] Gosman, A.D., Pun, W.M., Runchal, A.K. and Spalding, D.B., Heat and Mass Transfer in Recirculating Flows, Academic Press, London (1969).

[3] Hjertager, B.H. and Mangussen, B.J., Calculation of Turbulence Three Dimensional Jet Induced Flow in Rectangular Enclosure, 9: 395-407 (1981).

[4] Gosman, A.D., Nielsen, P.V, Restivo, A. and Whitelaw, J. H., The Flow Properties of Rooms with Small Ventilation Openings, Trans.ASME, J. Fluid Engr., 102 (1980).

[5] Holmborg and Einborg, Flow Behavior in a Ventilated Room Measurement and Simulation, Department of Building and Construction, Royal Institute of Technology, Kthsyd, Sweden (2003).

[6] Zhang, J.S., Christianson and Riskowski, G.L., Detailed Measurements of Room Air Distribution for Evaluating Numerical Simulation Models, ASHRAE Transactions (1992).

[7] Mora, L., gadgil, A.J. and Wurtz, E., Comparison Zonal and CFD Model Predictions of Isothermal Indoor Air Flows to Experimental Data (2002).

[8] Sakamoto,Y. and Matsu, Y., Numerical Predictions of Three Dimensional Flow in a Ventilated Room Using Turbulence Models, Appl. Math. Modelling, 4 (1980).

[9] Chen, Q., Prediction of Room Air Motion by Reynolds Stress Models, Building and Environment, 31 (1996).

[10] Chen, Q. and Xu, W., A zero-Equation Turbulence Model for Indoor Airflow Simulation, Energy and Buildings, 28 (1998).

[11] Launder, B.E. and Spalding, D.B., The Numerical Computation of turbulent flows, Computer Methods in Applied Mechanics and Engineering, 3: 269-289 (1974).

[12] Awbi, H.B., Ventilation of Building, E. and FN Spon, London (1998).

[13] Versteege, H. and Meer, W., An Introduction of Computational Fluid Dynamics (1995).

[14] Choi, H.L. and Albright, L.D., Modeling the Effects of Obstructions in Slot-Ventilated Enclosures, American Society of Heating, Refrigeration and Air-Conditioning Engineers, Atlanta, GA. (1989).

[15] Mohammed, W.S., Space Air-Conditioning of Mechanically Ventilated Rooms, Ph. $D$. Thesis, Cranfield Institute of Technology (1986). 


\title{
نمذجة عددية للجريان الاضطر ابي في غرفة ذات تهوية قسرية
}

\author{
خضير سالم مشتت \\ كلية الهندة - جامعة ذي قار - ناصرية - العراق \\ المستخلص. في هذا البحث تم استخدام نمــوذج الاضــطر اب(ع-k)

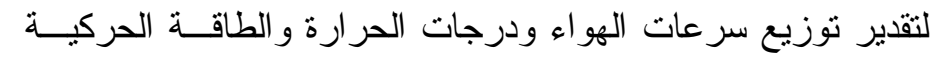 \\ للاضطر اب في غرفة مكيفة قسريا ولمو اقع مختلفة من فتحات دخول

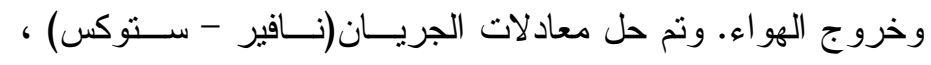

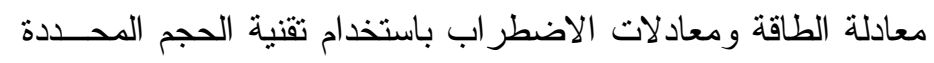

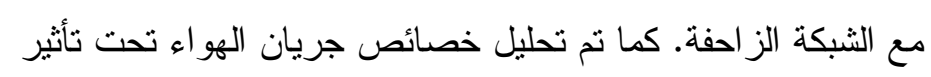

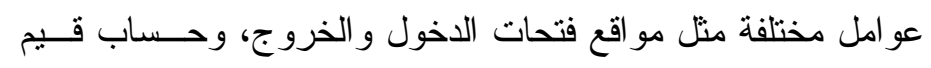

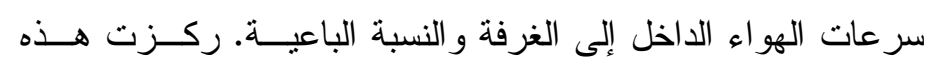

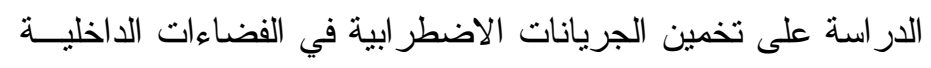

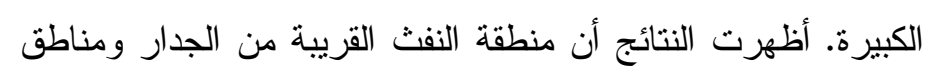

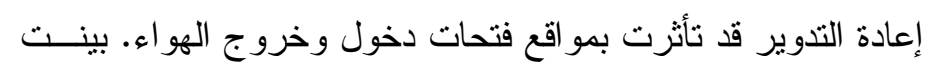

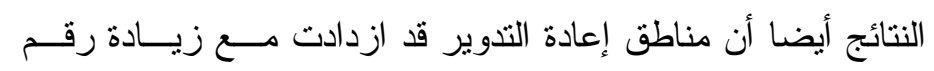 \\ رينولدز، بينما تقل هذه المناطق مع نقصان النسبة الباعية.
}

